This is an Accepted Manuscript of a book chapter published by Routledge in the book:

\title{
Routledge Handbook of Chinese Culture and Society
}

\author{
Published IN 2020
}

Book available online:

https://www.routledge.com/Routledge-Handbook-of-Chinese-Culture-andSociety/Latham/p/book/9780415830584 


\section{Rural Migrant Workers in Chinese Cities}

Wanning SUN, University of Technology Sydney

Since the start of economic reforms in the late 1970s, internal migration, along with urbanisation, has brought about the most profound social changes in China. With China's rural migrant workers numbering in the hundreds of millions and dominating the labour market in the country's fastest growing regions, this group embodies China's most intractable problems of socio-economic stratification. For this reason, the experiences of this social group have become an important area of inquiry. Centring on the figure of rural migrants in Chinese cities, this chapter aims to do three things. First, it provides an account of how the hukou system - the residential registration system — has shaped the pattern of China's rural-to-urban migration and the formation of the socio-political identities of migrant individuals. This is followed by a discussion of the diversity and internal differences within the rural migrant cohort, paying attention to how gender, place and type of employment intersect to shape varying levels of subaltern subjectivity and political consciousness. Finally, the chapter reviews the main perspectives from both critical scholarship and public discourses on the subjects of rural-to-urban migration and the experiences of rural migrant individuals.

\section{Hukou System, Migration Pattern and Rural Migrant Identities}

Since its implementation in the late 1950s, China's long-standing and deeply ingrained hukou system has effectively differentiated the nation along urban-rural lines, with up to seventy percent of the population having rural hukou. While the 
system effectively restricted individual mobility during several decades of socialism, it has also created a legal and practical distinction between peasants (who have rural hukou) and non-peasants (who have urban hukou). The rigidity of the system means that people born into families with rural hukou have had great difficulties converting to urban hukou status. It is also intrinsically discriminatory, since those with rural hukou are not entitled to urban privileges, including employment (especially employment in the public service sector), public education, public health cover, subsidised housing and a wide range of other state-provided benefits. This system of differentiation accounts for the two-tiered nature of citizenship in the People's Republic of China (PRC). Since the onset of economic reforms, both the state and the market have come to recognise that rural migrant labour is essential to the market economy and the development of urban China, and so both parties have encouraged and facilitated the entry of rural migrants into the city.

This is not to suggest that the rural-to-urban movement in the era of economic reforms was without its historical antecedents. Plenty of research points to the periodic movement of the rural population to the city prior to the implementation of economic reforms (Chi and Zhu 2004; Solinger 1999; Zhang 2001). Nor is it to suggest that the rural-to-urban movement since the start of the economic reforms was always a smooth and easy process. In comparison with younger cohorts of rural migrants who came to the city since the late 1990 s, the first generation of rural migrants who came to the city in the 1980s experienced not only the physical and spiritual anguish of loneliness and the contempt of urban residents, but they were also subject to much greater punishment. For instance, up to the 1990s, rural migrants were required to register with the local authorities and produce temporary residency permits, and were often 
subjected to random searches. Failure to present ID cards, temporary residency permits and other required documentation would result in rural migrants being sent back home, detained, charged monetary fines and harassed, often brutally, by the police. It became apparent in the 1990s that urban residents' improved livelihoods and China's staggering increase in GDP were achieved on the backs of millions of rural migrant workers. Yet, for a long time, rural migrants were referred to derogatorily, both in popular language and policy statements, as members of a 'floating population' (mangliu), who were seen to be drifting aimlessly and causing fear, anxiety and disorder in the city (Dutton 1998). Li Zhang (2001) argues that the public and official discourses of the floating population in the late 1980s and 1990s dehumanised and abnormalised the migrant population, and functioned as an essential part of the social control and governmental surveillance of rural migrants. In these discourses, the migrant population was portrayed as an 'amorphous flow of undifferentiated labourers without histories', and migrants were seen as 'flocks of raw labour that can be used and expelled at any time (Zhang 2001: 31).

Despite this rough beginning, rural migrants have continued to arrive in the city en masse in search of employment and economic opportunities (Chan and Buckingham 2008; Solinger 1999; Wang 2005; Zhang 2002). The 2013 Chinese Census reveals that the number of rural migrants has reached 262 million, constituting more than a quarter of the world's mobile population (Zhonghua renmin 2013). Among the internal migrant cohort, the majority is of rural origin, and by 2010 as many as fortyseven percent of them were born after 1980, fast becoming the mainstay of China's labour force (Xinhua 2011). 
While the relaxation of some aspects of the hukou system has led to mobility across the country on a massive scale, and while the regulatory and social control mechanism has become less punitive, discrimination remains. The reforms of the hukou system have not in the least done away with the discriminatory mechanism of the system. The two-tiered form of citizenship continues to play a pivotal role in shaping the systematic practice of social exclusion against the rural population. Such exclusion manifests itself most tangibly in the unequal distribution of a range of social benefits, including health care, education, housing and employment (Chan and Selden 2013; Chan and Buckingham 2008; Dutton 1998; Jacka 2006; Pun 2005; Solinger 1999; Wang 2005; Zhang 2001, 2002). While a small percentage of migrant workers have achieved significant gains in socio-economic status - enabling them to obtain urban hukou — the majority still subsist as dagong individuals (originally a Cantonese expression meaning 'working for the boss'), retaining rural hukou and finding it difficult, if not impossible, to develop a sense of belonging in the city. This acute sense of a lack —of prospects and direction — is particularly pronounced among young migrant workers. In comparison with older generations, who may have made some money and returned home, second-generation rural migrant workers born after the 1980s and 1990s, and increasingly those born in the new millennium, are more determined to stay in the city, despite the precarious nature of their employment options and living circumstances, and despite their uncertain future in terms of marriage prospects and a sense of belonging in the city.

With the exception of domestic workers, more than fifty percent of whom live in their urban employers' home (Sun 2009), most dagong migrants live in one of three common arrangements: a rental property (usually shared with other migrant workers) 
on the periphery of the city; on the premises of the shops, businesses and construction sites that employ them; and in dormitories provided by their employers (Solinger 1999). In terms of gender, 66.4 percent are men, meaning that women now account for a third of all rural migrant workers (Zhonghua renmin 2013). While factories in southern China mostly employ young, single women and men (Pun 2005), migrants in other areas are much more varied. Some are married but with their spouse and child back home; others have their spouse in the city, but not necessarily living with them. The phenomenon of migrant workers' children being left in the care of relatives in the home village is widespread.

The percentage of young migrants is increasing. By 2010, as many as 42.8 percent of migrants were born after 1980, making this age group the 'mainstay' of China's labour force (Huang 2011). The marital status of rural migrants is also changing. While a 2006 survey indicated that up to eighty percent of the migrant labour force was married, a 2009 survey suggests that this figure has dropped to twenty percent, implying that eighty percent of the current migrant labour force is now single. In both spatial and temporal terms, this state of liminality — being neither here nor there, and finding it hard to negotiate the past and future — creates among migrant workers a widely and deeply felt existential angst (Chan and Pun 2010; Sun 2010).

Rural migrant workers are commonly referred to as 'nongmingong'. Literally meaning 'peasant worker', this is a loosely applied term describing a person of rural hukou who has come to the city to dagong. However, while the expression is very widely used to refer to rural migrant workers, there is a paradox in its use. On the one hand, it captures the ambiguous socio-economic identity of this large social group: 
without an urban hukou, they are by definition rural residents, yet they are employed in the city as workers. On the other hand, using this generic label runs the risk of mistaking the experiences and activities of one sub-group of migrant workers for those of the whole. Moreover, the cultural politics of such naming, and its impact on the self-perceptions of rural migrant workers, is not clearly understood. Some advocates from rural migrant empowerment organizations with whom I discussed the issue argued that the term 'nongmingong' is insulting to rural migrant workers as it insists on labeling people as 'peasants' even though they may no longer work-or may never have worked — as peasants. These advocates also argue that the term provides moral cover for denying rural migrant workers the rights and entitlements that are available to urban workers who occupy similar roles. Further, from my conversations with many young factory workers, as well as with women in the service and hospitality sector, it is clear that while they generally described themselves as dagong individuals, most of these individuals did not identify themselves as nongmingong; they thought that this was a term reserved for rural migrants who worked on construction sites. The label is also potentially essentialist, in that it can encourage the assumption that some forms of rural migrant experience are more authentic and representative than others. However, despite the contested and extremely fraught nature of the label, it continues to be widely used in policy statements, media reports and academic papers, as well as within some migrant worker NGOs.

Similarly, much has been said about the complex and fraught nature of the dagongmei as a social identity. 'Dagong' is a Cantonese expression which means 'working for the boss' and dagongmei refers to the migrant women workers. On the whole, 
although originally known for her 'docility', 'nimble fingers', and 'pure and productive body' (Pun 2005) — all suitable for production on the assembly line - the term dagongmei has evolved to become a general term describing all rural migrant women offering their cheap labour in a wide range of occupations in exchange for monetary and other material gains. In south China, dagongmei are often referred to as bei mei (northern girls), but who is a northern girl depends on the person using the term and, more importantly, where the term is used. In Hong Kong, a bei mei is a migrant woman worker from mainland China, often engaged in the sex industry. To local residents in Guangdong Province, bei mei refers to any Chinese woman who is north of Guangdong. Similar geocentric and sexist logic works in terms such as wailaimei (women from outside) used in Shanghai, and dalumei (women from the mainland) used in Taiwan. But the configuration of bei mei, which is almost always derogatory in use, is not just geographical. It is also moral-sexual. In Hong Kong, it is often used to describe prostitutes working either in Hong Kong (like the woman in the film Durian Durian) or southern cities such as Shenzhen (Cartier 2001: 193). In Bei $M e i$, a novel by Sheng Keyi, the term bei mei describes women who practice a new moral economy of sex regardless of their occupation. The northern girls in the novel include cleaners, hotel room attendants, waitresses, domestic servants, company receptionists, as well as sex workers. In other words, although bei mei are indelibly associated with sexual transgression, they are not necessarily synonymous with sex workers, despite the fact that 'northern girls' can work as sex workers. In her groundbreaking ethnography of factory workers in south China, Pun Ngai argues that dagongmei (migrant women workers) is a 'specific Chinese subaltern' (Pun 2005: 15) and, as such, 'is a specific cultural-symbolic artefact as well as a worker-subject, 
constituted at the particular moment when transnational capital came to China in the postsocialist period' (Pun 2005: 18).

Rural migrant workers are different from earlier state sector workers, who were part of the low-wage system that minimised wage differentials and maximised universal welfare benefits. They are also different from new state sector workers, who are urban residents and enjoy the benefits of state subsidies for housing, health insurance and pensions. While workers in both the old and new state sectors are considered the backbone of China's working classes, the question of the class status of the nongmingong is still open to debate. If we are to apply a Marxist definition of class, nongmingong, who are peasants working in the city, do not constitute a class. For this reason many analysts, invoking a Weberian notion of economic, political and social status, prefer to consider rural migrants as constituting the bottom stratum of contemporary urban China (e.g. Li 2004). Others prefer to view them as part of the 'new working class' (Carrillo and Goodman 2012) or 'rural migrant working class', and position them somewhere on an 'arc of incomplete proletarianization' (Chan and Selden 2013). Some recent research (e.g. Zavoretti 2017) also suggests that if we consider rural migrants from the perspective of income, consumption and lifestyle, class formation, rather than hukou, has become more relevant to understanding 
Within the nongmingong cohort, there are vast differences, including the wide range of occupations they pursue. As early as the late 1980s it was possible to identify the six most common types of employment undertaken by China's rural migrants: manufacturing, service and hospitality, construction, cottage-style garmentprocessing, garbage- and scrap-collecting and domestic work (Solinger 1999). A recent survey of rural migrant workers reveals some shifts in this profile, listing the following six major areas of employment: manufacturing (35.7 percent); construction (18.4 percent); domestic and other services (12.2 percent); retail and small businesses (9.8 percent); transport, storage, and postal delivery (6.6 percent); and restaurant and hospitality (5.2 percent). In terms of gender, 66.4 percent are men, meaning that women now account for a third of all rural migrant workers (Zhonghua renmin 2013). A small number of migrants are employed in various forms of the sexualised service industry, such as sex workers and bar hostesses (Zheng 2004; Jeffreys 2004).

The internal differences within the rural migrant worker group can be appreciated in sociological terms, including the worker's relationship to the employer, labour conditions, level of organised representation, skill level, gender, age, marital status and parental status. Differences can also be found in everyday practices, including workers' everyday lives in the city, ranging from their capacity to partake in urban consumption, their relationship to the city and city life, living arrangements, as well as their level of attachment to the land, family and village life. Finally, the differences can be listed in cultural terms, manifesting themselves in one's sense of identity, belonging and subjectivity, as well as the affective landscape of individualsanxieties, hopes, fears, and desires pertaining to the future and the city. 
It is clear that working conditions, wages and the labour politics of stateowned enterprises are diverse across the manufacturing sector, but evidence suggests that urban workers in state owned enterprises (SOEs) fare much better than nongmingong workers in terms of livelihood and job security (Unger and Chan 2007; Lee 2002, 2007a, 2007b). Having said that, it is also true that urban employees who are either "retired" or laid off in the process of industrial restructuring in the 1990s have had to join the ranks of the "urban poor" and become recipients of the Minimum Livelihood Guarantee (zuidi shenghuo baozhang) when their family income falls below a locally-set poverty line (Solinger 2010). For the first time, many of these workers must compete directly with nongmingong for jobs.

It is also possible that a particular structure of grievances may arise from the unique set of issues confronting an individual migrant worker in any given employment group. For example, domestic workers' feelings and pride are chronically injured due to a lack of respect from their employers (Yan 2008; Sun 2009; Hu 2011); construction workers often do not get paid on time or at all (Pun and Lu 2010a, 2010b); and factory workers must cope with the feeling of alienation that comes from working twelve hours on the assembly line (Sun 2012a). On the other hand, from the point of view of employers and urban residents, a particular type of emotional response may dominate their perception of a specific migrant group. Thus, for instance, the domestic worker commonly elicits distrust from employers; the construction worker arouses public compassion and anxiety; and the sex worker provokes disgust and moral hatred. Cultural differences can also be seen in the great diversity of experiences with media and information technologies. For example, older 
construction workers often have little exposure to television, news, reading materials or the Internet, while younger factory workers commonly have access to a wide variety of entertainment sources, including computer games in Internet cafés and mobile technologies such as the mobile phone, as well as regular participation in social media.

Between construction workers and factory workers, there is one profound difference in terms of contractual terms and conditions. Factory workers are paid monthly wages, as agreed in their contract, whereas most construction companies, which do not sign contracts with workers, do not pay wages on a regular basis. Instead, they make payments at the end of the year, or when the worker leaves the job. Moreover, the rate of pay and other conditions are often based on verbal agreements between the worker and the company, and are often arranged through intermediaries (Pun and Lu 2010a, 2010b). As a result, wage arrears and labour disputes are pandemic within the construction sector in urban China. In fact, unpaid wages seem to be the norm rather than exception.

Sociological scholarship on rural migrant construction workers tells us that there are at least three reasons for the phenomenon of wages arrears. First, there is no workers' union in China that operates independently of the Chinese state and functions effectively to protect the rights of rural migrant workers. Second, despite the government's requirement for construction companies to sign labour contracts with individual workers, only a small percentage of workers enter such a contractual relationship, and most rural migrants work on a casual basis. Third, the construction industry in reform-era China is characterised by a complex and complicit arrangement 
between the state and capital, resulting in a multiplicity of (sub)contractual tiers, with intense competition and clear demarcation of labour roles within each phase of construction (Pun and Lu 2010a, 2010b). The widespread, entrenched and consistent problems of wage arrears and wage reduction have bred what Pun and Lu call a 'culture of violence' (Pun and Lu 2010a) among migrant construction workers and deep-seated hostility between the management and workers. Well-publicised in the media and vivid in urban residents' imagination are the perennial incidents of rural migrant construction workers threatening self-harm, often in public and spectacularly desperate ways, in order to force their bosses to pay the wages owed to them. The first reported incident of rural migrant workers threatening suicides on top of tall buildings took place towards the end of 2002, precipitating a steady and widespread increase in similar incidents across the country in the subsequent year or so, within a general frame of portraying with sympathy the social and economic injustices experienced by rural migrants (e.g. Chen 2004; Wei 2004). As one Chinese commentator observes of these migrant workers' choiceless choice, 'when the public and social mechanism of seeking justice cannot operate as it should, and where rational and legal channels of voice-seeking are blocked, unusual, extraordinary, and individually devised means become the only choice available' (Xu 2007).

Besides construction work, factory work in the Pearl River and Yangtze River Deltas has absorbed nearly forty percent of the total mobile population (Li 2004). Furthermore, factories are also places where a young generation of rural migrants - in their late teens and twenties - concentrates. Born in the 1980s, and 1990s, and the beginning of the new millennium, they are better educated in comparison with migrant workers in other occupations, such as domestic workers, construction workers and small business retailers. 
Furthermore, in contrast to the older migrants who see themselves as sojourners in the city, most factory workers are single and have a much more tenuous connection with the land. In fact, most have very little, if any, farming experience and skills before coming to the city, and many of them are not interested in going back. These young workers are at marriageable age, and yet many face difficulties in finding a suitable marriage mate or maintain a stable intimate relationship (Sun 2017a, Sun 2017b).

In comparison with construction workers, factory workers are subject to a much higher level of discipline within the industrial regime. Industrialization entails putting in place a range of spatial and institutional practices in order to turn 'a young and rural body into an industrialised and productive laborer' (Pun 2005: 77), thereby transforming 'lazy and unproductive' laborers' 'bodies and minds, behaviors and beliefs, gestures and habits, and attitudes and aptitudes' (Pun 2005: 79). Factory workers are also thought to be the most rights-conscious cohort among rural migrants, as evidenced by the sporadic, though not uncommon, strikes and other forms of collective action at China's factories (Leung and So 2012). A combination of the rigidity of industrial management rules and a loss of emotional connection with their cultural background, as well as an inability to belong to and identify with the city, produces among young workers a prevailing sense of alienation, despair and existential uncertainty, leading them to question the meaning of life and the worth of work.

The most well publicised incidents involve the suicides and suicide attempts of more than a dozen young workers at Apple's Foxconn factory in Shenzhen between January and November 2010. Foxconn is a large contract manufacturer producing parts for a 
variety of companies, including Apple, Dell, HP, Motorola, Nintendo, Nokia and Sony. As a response to these suicides, Foxconn announced the decision to increase wages for its workers, and as a preventative measure, the management installed suicide-prevention netting, and asked employees to sign pledges not to commit suicides. Investigating the context and background to the workers' suicides, Chan, Pun and Selden turn their attention to the broader political-economic context of the buyer-driven value chain, in which Apple establishes parameters and control over price-setting, production processes and product delivery from its suppliers, notably Foxconn. Analyzing the consequences of this asymmetrical power relationship, the authors show that as the scale of production has ramped up, Apple's 'value capture' and profits have soared while Foxconn's margins have flatlined, leading to massive intensification of work and a harsh workplace managerial regime (Chan, Pun and Selden 2013).

Although it is the construction workers and factory workers who often capture public attention, it is the rural migrants in other lines of employment, such as service, hospitality and domestic workers, who prove to be indispensable to urban residents. Apart from sex work, domestic work is perhaps the most gendered form of employment taken up by rural migrants. However, unlike their dagongmei counterparts employed on the factory production lines, who live in the 'dormitory labor regime' and are mostly young — between twenty-two and twenty-four years old—and single (Pun 2007; Pun and Smith 2007), migrant domestic workers can be anywhere from fifteen to over seventy years old (most of them are clustered from their late twenties to forties), and many of them are married with children. Having no urban hukou and therefore living as transients in the city, most migrant domestic 
workers dwell in one of three kinds of accommodation: full-time domestics have livein positions with their employers; part-time and day-time domestics tend to rent rooms in farmhouses outside Beijing, traveling long distances to work in urban and suburban homes; and casual cleaners/domestic helpers sleep in dormitories provided by the residential property management group (wuye guanli) that employs them, usually in the basements of the residential apartment buildings they service. Part-time domestics, who generally live with their spouses and children in rented rooms, are able to sustain a more stable family life than full-time and casual workers. But regardless of these differences in living arrangements, most migrant domestic workers tend to see themselves as sojourners in the city to varying degrees, and refrain from making emotional, psychological or practical investments accordingly. This also discourages their urban employers from investing in and cultivating long-term relationships with them.

Disputes between employers and their domestic employees are legion. Domestic workers regularly complain about their ungenerous wages; the scarcity of time for rest, recreation and holidays; and their employers' distrust, fussiness, lack of respect and downright contempt for their maids (Gaetano 2004; Jacka 2006). While reputable agencies try to mediate between the two parties, most wash their hands of this responsibility once introduction fees from employers and domestic workers have changed hands. To date, there are no legally binding contracts specifying employers' and domestic workers' respective responsibilities, nor is there legislation stipulating minimum wages, basic working conditions and rights and benefits for domestic workers. Unlike factory workers and many other categories of employees, domestic workers are not protected by labour law, have no guaranteed time off or paid leave 
and enjoy no entitlement to health care, retirement or other benefits. Beijing's Domestic Service Center does recommend to employers that live-in maids be given at least two days off each month, are allowed at least eight hours of sleep each day and are paid extra for working on public holidays and New Year's Day. But such recommendations are not legally binding, are left to the discretion of employers and are frequently ignored.

\section{Rural Migrants in Critical Scholarship and Public Discourses}

One of the earliest and perhaps the most encompassing work on rural migrants and internal migration is Dorothy Solingers's book Contesting Citizenship in Urban China (1999). This book provides a comprehensive account of the range of discriminations experienced by rural migrants in the Chinese city. Restricted by their non-urban hukou, most rural migrants are limited to jobs that are dirty, dangerous, difficult and low paying — jobs shunned by urbanites. Most importantly, these jobs are without the sort of benefits and remuneration packages that are taken for granted by urban workers. Job opportunities aside, having a rural hukou also excludes migrants from claiming an entire range of other urban entitlements, including education, housing subsidies and medical care, effectively turning these sojourners into secondclass citizens. Also engaging with the question of urban citizenship, Li Zhang's study of the spatial politics of 'Zhejiang Village' in Beijing uncovers a number of ways in which 'urban citizenship' administered through the hukou system discriminates against rural migrants, by curtailing their entitlement to claim urban space (Zhang 2001, 2002). Subsequent anthropological work on rural migrants tends to focus on a particular line of employment, including factory work in south China (Pun 2005), the 
construction sector (Pun and Lu 2010a, 2010b), domestic work (Yan 2008; Sun 2009;

Hu 2011, the service and hospitality sector (Hanser 2008; Otis 2012) and sex work (Zheng 2009). These works document migrants' working conditions and living circumstances, as well as the impact of mobility on rural migrants' lives, and it is possible to discern a few common concerns.

Rural migrants have been a prominent empirical figure in the critique of the suzhi (quality) discourse. Yan Hairong, who has maintained a long-standing interest in the figure of the domestic worker as an object of governmentality, has convincingly demonstrated the importance of the suzhi discourse in the process of subject formation. Her study of the maid-employer relationship argues eloquently that subject-making, be it cosmopolitan or subaltern, is not an 'enclosed', isolated process involving a singular subject, but is rather a 'problematic, open-ended, and relational process relying on interplay between subjects' (Yan 2006: 246). Similarly, Ann Anagnost juxtaposes the figure of the rural migrant with that of the urban middle-class 'only child' in order to argue that suzhi codes the difference between these two social groups by derogating migrant bodies and sanctioning the "transfer of economic value from one body to another' (Anagnost 2004: 191). She argues further that the suzhi discourse "works ideologically as a regime of representation through which subjects recognise their positions within the larger social order' (193). In addition, Jacka (2006, 2009) suggests that the potency of the suzhi discourse derives from its capacity to generate affect, including both the desire for higher levels of suzhi for oneself and sympathy and contempt for others who have less. Also considering the experience of the domestic worker, Sun takes the critique of suzhi in another direction and argues that public statements about the quality of individuals increasingly take on an external, 
spatial and geographic dimension. In other words, the possession or lack of suzhi by an individual or group seems increasingly attributable to place of origin. She argues that an understanding of the ways in which the mobile body is inscribed with difference is crucial to uncovering the variegated processes commodifying and objectifying the migrant body. Furthermore, she extends the suzhi debate into the realm of popular culture and explores how television's most watched genre- the drama series - represents the figure of the maid. She argues that popular media and cultural productions have a crucial role in constructing rural migrants as wanting in suzhi and in need of development, education and civilization (Sun 2009).

Critiques of how suzhi is deployed in the management of rural migrants also provide crucial clues to understanding how rural migrants are discursively constructed in both state-authorised discourses and popular cultural expressions. Widespread socioeconomic stratification has not only led to the marginalisation of workers in material senses, it has also given rise to the 'culture of inequality' (Sun 2013), evidenced in the hegemonic language of the urban, consumer-oriented middle class, along with the marginalisation of workers' and peasants' voices. The state, capital, international NGOs and transnational cultural elites all jostle to speak for and on behalf of China's rural migrant workers, and the sexuality of rural migrant women is an integral dimension of the constructed dagongmei identity. For instance, the sexuality of dagong individuals — men and women — is portrayed in policy and academic discourses as a source of social instability and moral disorder.

Migrant workers are typically described as members of the 'three-low communities'-low income, low literacy and low consumption power-and are 
therefore not the primary target audience for commercial media. Stratification is most pronounced in the media and popular culture industry targeting women. While capital, including domestic and transnational capital, targets upwardly mobile, young and educated urban Chinese women, vast numbers of rural women, including rural migrant women, have few media outlets that speak to or give voice to them, apart from the magazine Nongjianu Baishitong (Rural Women Knowing All) (Jacka 2004; Zhao 2008). Lan Ling (Journal for Migrant Women), the only monthly magazine which explicitly gave voice to migrant women, had to close down in late 2007 due to lack of funding.

Popular media, consisting of tabloid, consumer and lifestyle media outlets, cater to a highly stratified readership (Zhao 2002; Sun 2004), despite their occasional sympathetic coverage of migrant workers and their sometimes populist sentiments. On the whole, migrant workers are portrayed in popular representations as sources of urban anxiety, fascination and fear, and thus tend to come across as needing to be controlled (Sun 2004, 2009; Zhao 2002) or as the raw material for civilizing, education and self-development efforts (Jacka 1998; Davin 1999; Dutton 1999; Sun 2004; Yan 2008). Commercial media also tend to focus on the rural migrant as a figure of criminality, the 'marriage wrecker', or the 'gold-digger' - a migrant worker marrying or offering sex to her geriatric employer in order to get her hands on his money and property and gain access to urban privileges (Sun 2009). A rural migrant can also be a naïve and unsophisticated outsider in town, though well meaning and trustworthy (Sun 2012b).

State media narratives urge rural migrants to engage in ceaseless self-improvement and develop a strong sense of self-respect, self-reliance and resilience, which are 
essential to, and are crucial manifestations of, achieving good suzhi (Jacka 2006; Sun 2009; Yan 2008). On the other hand, they also actively explore ways of representing rural migrants in ways that make them feel appreciated and included. This is largely due to the fact that the management of the social conflicts that result from this growing inequality and stratification has become a top priority in the state's efforts to maintain stability (weiwen). Since the mid-2000s, the discursive regime of 'social harmony' has become the 'main melody' in Chinese politics, forming an integral part of the co-ordinated and orchestrated machinery of stability-maintenance. In this discursive regime, rural migrant workers, regarded as one of the most destabilising factors, figure increasingly prominently. Along with this focus in the political realm, the figure of the nongmingong (rural migrant worker) has also become a favourite subject matter in documentary films that focus on marginal identities. These media products are usually didactic in content and tone. Despite the unreserved praise and generous accolades given to rural migrants, rural migrant individuals appear in the series only to be seen, rather than heard. Their experiences in the city-happy, sad, frustrating or humiliating — are narrated through the voice-over, functioning to give context and substance to the general argument being made about recognition.

This does not mean that migrant workers are content with silence (Jacka 1998). Against all odds and with varying degrees of success, they have formed strategic alliances with various social forces, including supportive scholars (Jacka 2004), NGOs, urban and middle class media practitioners, the government (e.g. the Women's Federation-supported newspaper Nongjianu Baishitong mentioned above) and the market sector. These alliances often, although not always, lead to some kind of cultural initiatives, such as maintaining websites and publishing newsletters, as well 
as the formation of arts and performance troupes, such as the Dagong Youth Arts Group in Beijing. In south China, life in the factory assembly line and dormitory regimes has given rise to a distinct 'dagong culture' consisting of songs, dagong poetry, a myriad of self-funded dagong media publications and online literature centring on dagong experiences. However, due to the perceived lack of commercial viability by publishers, its impact and reach is limited.

The Chinese media tend to deal with urban themes (although rural migrants may feature in such representations) and speak to urban interests and concerns (Zhao 2002, 2008). At the same time, Chinese media consumers are divided into those with urban household registration and those with rural household registration, the latter group including rural migrants in the city. It is often easy to forget that although migrants come to the city primarily as a form of cheap labour, they also figure significantly as consumers in the urban marketplace, including as consumers of urban-oriented media. While in many cases consuming urban-centric media and popular culture can be an essential aspect of their encounter with modernity, the reality is that they have little option but to negotiate with the content of these products, which, on the whole, do not defend their interests or advocate their points of view.

The support of the state, NGOs and various other organisations for rural migrants often produces complex and ambiguous results. As Jacka's (2006) fieldwork in Beijing shows, migrants are reluctant to accept all aspects of the migrant subject positions assembled by the Migrant Women's Club (under the auspices of the All China Women's Federation and funded by the Ford Foundation) and the collective that publishes Nongjianu Baishitong. Over recent years a state-initiated policy has been promoting media coverage of rural themes and issues in news and current affairs, as part of the latest ideology of 'building a new socialist countryside'. As part of the 
official discursive exercise of building social harmony, state media have consciously promoted positive stories featuring model migrant workers and endorsing their contribution to China's modernisation process.

Recent research shows that migrants are not passive recipients of a set of cultural practices determined by their socio-economic role or the cultural narratives with which they engage, nor are they inventing their own practices de novo (Sun 2012c; Sun $2012 d_{2}$ Sun 2014). Workers' media practice also takes the form of adopting new media and communication technologies to produce alternative materials as testimonials to workers' work conditions, labour disputes and the everyday reality of marginalisation (Xing 2012). For instance, migrant workers have become increasingly savvy with the use of new media technologies to protect their rights and publicise individual experiences of injustice, including work-place injuries, failure to receive wages and unacceptable working and living standards (Tong 2012). Qiu (2009) refers to these incidents as 'new media events'. Contrasting them with televised events, rituals and ceremonies, which are sleek in presentation, grand in scale and often take place in important spaces, Qiu argues that these media practices, enabled by the Internet and new media technologies, nevertheless have the capacity to raise public awareness and effect real social change, even though they are small in scale. However, research also cautions against a narrow political empowerment narrative. After all, most rural migrant workers use mobile phones to cope with boredom and alienation. Although they use camera phones for "representing the world, constructing the self, transcending limited circumstances, envisaging new possibilities, and planning for the future" (Wallis 2013, 121), not all these practices lead to collective actions or the improvement in 'digital-political literacy' (Sun 2014: 178). 
Worker activists also engage in various forms of creative practice, such as dagong poetry and fiction. Whereas one could be forgiven for thinking that dagong life in the industrial heartland, notorious for its low pay, high levels of alienation and punishing effects on the body and soul, is hardly the ideal stuff for poetry, the truth is that long work hours and lack of tertiary education have not stopped many literary-minded workers from creating poetry for self-expression. For many worker-poets, writing poems is no longer an idle pursuit; it is about finding meaning and purpose in an otherwise meaningless existence. Many lines from dagong poetry, for instance, have been transformed into lyrics by activist songwriters and performers, enabling them to be 'read' and performed in a variety of formats. Sun Heng, a well-known workersinger and songwriter from the New Worker Art and Cultural Festival in Picun, rural Beijing, regularly puts music to dagong poems, and performs them to migrant worker audiences. Also, lines from dagong poetry are often chosen to accompany the visual presentations, installations and exhibitions showcasing the work and living conditions of workers, leading to a range of highly dispersed and unpredictable modes of distribution, available to both workers and urban consumers. Finally, most workerpoets utilise online spaces, particularly blogs, to publish their work and engage in dialogue with readers (Sun 2012a). This approach allows these writers to bypass the conventional institution of publishing. At the same time, the online reputation of some of these writers has led to book contracts with more traditional publishers.

Migrant workers write blogs on dagong lives, and activists and leaders from the worker community effectively use Weibo (a micro-blogging platform similar to Twitter) to inform, mobilise, organise and coordinate collective actions against 
capitalist management (Qiu 2012). Other activists produce visual materials, including videos, documentaries and photography, for the primary purpose of raising awareness among the wider community, as well as class consciousness among the workers. Although these grassroots media practices can hardly compete with mainstream media in terms of the scale of production and level of exposure, they nevertheless represent some nascent media forms and practices that have been made possible by the advent of digital visual technologies and online spaces (Sun 2012c). It has been observed that with the exceptionally high level of uptake of mobile phones and social media platforms such as QQ (a Chinese version of Skype) by rural migrant workers, engagement in new media practices has become an integral aspect of the very fabric of the everyday experience of the worker, especially workers that belong to the younger generation (Qiu 2009). In other words, workers' media practices should no longer be considered as external to workers' socio-economic experience as industrial labourers. They are part of the same experience.

\section{Concluding Remarks}

The world has grown increasingly fond of talking about 'China's rise' and a 'prosperous China', as well as the country's fast growing middle class and emerging super-rich. But beneath this prosperous image lies a different China consisting of myriad marginalised social groups. The individuals comprising these groups, each with a modest dream of greater equality and less discrimination in their often bleak and harsh lives, cast a disquieting shadow over the vision of a rejuvenated China with common prosperity that is the stuff of President Xi Jinping's 'China Dream'.

Paramount among these groups are the nation's workers and peasants who, in the 
socialist era, were hailed as one of most progressive forces in history, and represented the most advanced agents of production. Now numbering more than 260 million and still growing, rural migrant workers constitute the core of China's post-socialist industrial working class and underclass, and are an embodiment of the country's most intractable problems of inequality, even though their labour has played a crucial role in enabling and sustaining the country's remarkable economic growth.

Despite this, it is equally important to realise that most rural migrants are motivated by a sense of hope, however tenuous it may be. This hope takes myriad forms, including hope for a better future for themselves and, more commonly, for their children. This hope may also be gender- and generation-specific. Research suggests, for instance, that a key motivation for migration for young women is to avoid early marriages and childbirth and secure a better future (Benyon 2004). We also know that rural young women in Beijing report enjoying relative autonomy from parental and hierarchical control and having freedom to choose an ideal mate (Gaetano 2004, 2015). In fact, rural-to-urban migration to the city has indeed begun to challenge gender relations in the village. Increasingly, rural migrant men not only need to compete with more wealthy urbanites and better off rural counterparts outside the family, they also have to make 'masculine compromises' at home, since migrant women may make more money than they do (Choi and Peng 2016). But hope operates as a double-edged sword. Many hope that one day they will be able to find a way to settle in the city, and that their hard work will give their children a better chance for the future. Rural migrants' hope is an important moral resource for both the state and the market. It dovetails with the needs of the Party for a motivated labour force. It is also an essential aspect of the neoliberal project to instill in rural migrants a strong, 
internalised optimism for improvement, so that they remain committed to playing their essential (albeit menial) role in creating and sustaining China's economic success. In this sense, individuals' hope may stand in the way of organizing largescale collective action aiming for a radical improvement of their political, social and economic circumstances. It may well be for this reason that so far, there is little evidence pointing to the capacity of workers to organize labor-rights-related actions on a large scale. In fact, research has also shown that the state continues to place severe restrictions on And it is not at all clear whether workers will be able to build their own autonomous unions and win the right to freedom of association - both essential to the effectiveness of the labor movement - any time in the near future (Chan, Pun, and Selden 2013). At the same time, we cannot rule out the possibility that rural migrants' determination to stay on in the city, which is also motivated by hope, may, in the long run, translate into a desire for a fairer and more equitable society.

\section{Bibliography}

Anagnost, A. (2004) 'The corporeal politics of quality (suzhi)', Public Culture, 16(2): 189-208

Beynon, L. (2004) 'Dilemmas of the heart: rural working women and their hopes for the future', in A.M. Gaetano and T. Jacka (eds) On the Move: women and rural-to- 
urban migration in contemporary China, New York: Columbia University Press, $131-50$.

Carrillo, Beatriz and Goodman, David S. G. (2012) 'Introduction: the sociopolitical challenge of economic change - peasants and workers in transformation', in Carrillo, Beatriz and Goodman, David S. G. eds. China's Peasants and Workers: Changing Class Identities, Cheltenham, UK: Edward Elgar: 1-15.

Cartier, C. (2001) Globalizing South China, Oxford: Blackwell.

Chan, J. and Pun, N. (2010) 'Suicide as protest for the new generation of Chinese migrant workers: Foxconn, global capital, and the state', The Asia-Pacific Journal, 37(2): September 13. http://japanfocus.org/-Jenny-Chan/3408.

Chan, J., Pun, N. and Selden, M. (2013) 'The politics of global production: Apple, Foxconn and China's new working class', New Technology, Work and Employment, 28(2): 100-15.

Chan, J. and Selden M. 'Class, hukou, and the new generation of Chinese rural migrant workers', paper presented at the Media and the Cultural Politics of Class in China Workshop, University of Technology, Sydney, December 2013.

Chan, K.W. and Buckingham, W. (2008) 'Is China abolishing the hukou system?', China Quarterly, 195: 582-606. 
Chen, H. (2004) 'Dazhong meijie yu shehui bianyuan ti de guanxi yanjiu: yin tuo qian nongmin gong gongzi baodao weili' [On the relationship between the mass media and marginalized social groups: a case study of media coverage of rural migrants' failure to receive payment], Xinwen daxue [University of Journalism], Spring: 6-10.

Chi, Z. and Zhu, L. (2004) Liumin shenghuo lueyin [A glimpse of mobile populations in Chinese history], Changchun: Shengyang chubanshe [Shengyang Press].

Davin, D. (1999) Internal Migration in China, London: Macmillan.

Choi, Susanne Yuk-Ping, and Peng, Yinni. 2016. Masculine Compromise: Migration, Family, and Gender in China, Berkeley: University of California Press.

Dutton, M. (1998) Streetlife China, Cambridge, UK: Cambridge University Press.

Gaetano, A.M. (2004) 'Filial daughters, modern women: migrant domestic workers in post-Mao Beijing', in A.M. Gaetano and T. Jacka (eds) On the Move: women and rural-to-urban migration in contemporary China, New York: Columbia University Press, 41-79.

Gaetano, Arianne. 2015. Out to Work: Migration, Gender, and the Changing lives of Rural women in Contemporary China. Honolulu, HI: University of Hawaii Press.

Hanser, A. (2008) Service Encounters: Class, Gender, and the Market for Social Distinction in Urban China. Stanford, CA: Stanford University Press.

Hu, X. (2011) China's New Underclass: paid domestic labour, New York: Routledge. 
Huang, C. (2011) Zhongguo xinshengdai nongmingong [China's New-Generation Rural Migrant Workers], Beijing: Renmin wenxue chubanshe [People's Literature Press].

Jacka, T. (1998) 'Working sisters answer back: representation and self-representation of women in China's floating population', China Information, 13(1): 43-75.

Jacka, T. (2004) 'Migrant womens' stories', in A.M. Gaetano and T. Jacka (eds) On the Move: women and rural-to-urban migration in contemporary China, New York: Columbia University Press, 279-85.

Jacka, T. (2006) Rural Women in Urban China: gender, migration, and social change, Armonk, NY: M. E. Sharpe.

Jacka, T. (2009) 'Cultivating citizens: suzhi (quality) discourse in the PRC', Positions: east Asia cultures critique, 17(3): 523-35.

Jeffreys, E. (2004) China, Sex and Prostitution, London: RoutledgeCurzon.

Lee, C.K. (2002) 'From the specter of Mao to the spirit of the law: labor insurgency in China', Theory and Society, 31(2): 189-228.

Lee, C.K. (2007a) 'Mapping the terrain of Chinese labor ethnography', in C.K. Lee (ed.) Working in China: ethnographies of labor and workplace transformation, London: Routledge, 1-12. 
Lee, C.K. (2007b) 'The unmaking of the Chinese working class in the northeastern rustbelt', in C.K. Lee (ed.) Working in China: ethnographies of labor and workplace transformation, London: Routledge, 15-37.

Leung, P. and So, A.Y. (2012) 'The making and re-making of the working class in south China', in B. Carrillo and D.S.G. Goodman (eds) Peasants and Workers in the Transformation of Urban China, Cheltenham, UK: Edward Elgar, 84-104.

Li, Q. (2004) Nongminggong yu Zhongguo shehui fengceng [Rural Migrant Workers and Social Stratification in China], Beijing: Shehui kexue wenxian chubanshe [Social Sciences Academic Press].

Otis, E. (2012) Market and Bodies: women, service work, and the making of inequality in China, Stanford, CA: Stanford University Press.

Pun, N. (2005) Made in China: women factory workers in a global workplace, Durham, NC: Duke University Press.

Pun, N. and Lu, H. (2010a) 'A culture of violence: the labor subcontracting system and collective action by construction workers in post-socialist China', The China Journal, 64: 143-58. 
Pun, N. and Lu, H. (2010b) 'Unfinished proletarianization: self, anger, and class action among the second generation of peasant-workers in present-day China', Modern China, 36(5): 493-519.

Pun, N. and Smith, C. (2007) 'Putting transnational labour process in its place: the dormitory labour regime in post-socialist China', Work, Employment and Society, 21(1): 27-45

Qiu, J.L. (2009) Working-Class Network Society: communication technology and the information have-less in urban China, Cambridge, MA: MIT Press.

Qiu, J.L. (2012) 'Network labor: beyond the shadow of Foxconn', in L. Hjorth, J. Burgess and I. Richardson (eds) Studying Mobile Media: cultural technologies, mobile communication, and the iPhone, New York: Routledge, 173-89.

Solinger, D.J. (1999) Contesting Citizenship in Urban China: peasant migrants, the state, and the logic of the market, Berkeley, CA: University of California Press.

Sun, W. (2004) 'Indoctrination, fetishization, and compassion: media constructions of the migrant woman', in A.M. Gaetano and T. Jacka (eds) On the Move: women and rural-to-urban migration in contemporary China, New York: Columbia University Press, 109-128.

Sun, W. (2009) Maid in China: media, morality and the cultural politics of boundaries, London: Routledge. 
Sun, W. (2010) 'Narrating translocality: dagong poetry and the subaltern imagination', Mobilities, 5(3): 291-309.

Sun, W. (2012a) 'Poetry of Labour and (Dis)articulation of Class: China's WorkerPoets and the Cultural Politics of Boundaries', Journal of Contemporary China, 21(78): 993-1010.

Sun, W. (2012b) ‘Screening Inequality: Injustices, Class Identities, and Rural Migrants in Chinese Cinema', Berliner China-Hefte: Chinese History and Society, Issue 41: 6-20.

Sun, W. (2012c) 'Amateur photography as self-ethnography: China's rural migrant workers and the question of digital-political literacy', Media International Australia, vol. 145:135-44.

Sun, W. (2012d) 'Subalternity with Chinese Characteristics: Rural Migrants, Cultural Activism, and Digital Video-Making', Javnost - the Public: Journal of the European Institute for Communication and Culture, 19(2): 83-100.

Sun, W. (2013) 'Inequality and culture: a new pathway to understanding social inequality in China', in W. Sun and Y. Guo (eds) Unequal China: the political economy and cultural politics of inequality, London: Routledge, 2013: 12-26. 
Sun, W. (2017a) 'Rural Migrants and Their Marital Problems: Discourses of Governing

and Knowledge Production in China', Critical Policy Studies,

https://doi.org/10.1080/19460171.2017.1369444

Sun, W. (2017b).Romancing the vulnerable in contemporary China: Love on the assembly

Formatted: Font: (Default) Times New Roman, 11 pt

line and the cultural politics of inequality, China Information,

https://doi.org/10.1177/0920203X17733594.

Tong, F. (2012) 'Wangluo shehui yu xing gongren jieji de xincheng' [The network Formatted: Font: (Default) Times New Roman, $11 \mathrm{pt}$ Formatted: Font: (Default) Times New Roman, 11 pt

Formatted: Font: $11 \mathrm{pt}$

society and the making of the new working class], unpublished MA thesis, Beijing University.

Unger, J. and Chan, A. (2007) 'Memories and the moral economy of a state owned enterprise', in C.K. Lee and G. Yang (eds) Re-envisioning the Chinese Revolution: the politics and poetics of collective memories in reform China, Washington, DC:

Woodrow Wilson Center Press, 119-40.

Wallis, Cara. (2013). Technomobility in China: Young Migrant Women and Mobile Phones. New York: New York University Press.

Wang, F.L. (2005) Organizing Through Division and Exclusion: China's hukou system, Stanford, CA: Stanford University Press.

Wei, F. (2004) 'Dazhong chuanmei yu nongmin huayu quan: cong nongmingong tiao lou xiu tan qi' [Mass media and rural migrants' rights to speak: a case study of rural 
migrants' acts of jumping off buildings], Xinwen yu chuanbo yanjiu [Journalism and Communication Studies], 11(2): 2-12.

Xing, G. (2012) 'Online activism and counter-public spheres: a case study of migrant labour resistance', Javnost - the Public, 19(2): 63-82.

Xinhua News Agency (2011) 'Zhongguo liudong renkou fazhan baogao 2011: 80 hou jian cheng liudong dajun zhujiao' [2011 report on China's floating population: post80s generation has become the mainstay of floating population], October 10 . http://news.xinhuanet.com/politics/2011-10/10/c_122134374_3.htm.

Xu, X. (2007) 'Zhongguo nong min gong weihe yi si kang zheng' [Why do Chinese migrant workers commit suicides to protest], Ershiyi shiji [Twenty-first Century], 100: $114-23$.

Yan, H. (2006) 'Self-development of migrant women and the production of suzhi (quality) as surplus value', in M.Y. Dong and J. Goldstein (eds) Everyday Modernity in China, Seattle: University of Washington Press, 227-59.

Yan, H. (2008) New Masters, New Servants: development, migration, and women workers, Durham, NC: Duke University Press.

Zavoretti, R. (2017) Rural Origins, City Lives: Class and Place in Contemporary

China, Seattle: University of Washington Press. 
Zhang, L. (2001) Strangers in the City: reconfigurations of space, power, and social networks within China's floating population, Stanford, CA: Stanford University Press.

Zhang, L. (2002) 'Spatiality and urban citizenship in late socialist China', Public Culture, 14(2): 311-34.

Zhao, Y. (2002) 'The rich, the laid-off, and the criminal in tabloid tales: read all about it!', in P. Link, R.P. Madsen and P.G. Pickowicz (eds) Popular China: unofficial culture in a globalizing society, Lanham, MD: Rowman \& Littlefield, 111-35.

Zhao, Y. (2008) Communication in China: political economy, power, and conflict, Lanham, MD: Rowman \& Littlefield.

Zheng, T. (2004) 'From peasant women to bar hostesses: gender and modernity in post-Mao Dalian', in A.M. Gaetano and T. Jacka (eds) On the Move: women and rural-to-urban migration in contemporary China, New York: Columbia University Press, 80-108.

Zheng, T. (2009) Red Lights: the lives of sex workers in postsocialist China,

Minneapolis, MN: University of Minnesota Press.

Zhonghua renmin gongheguo guojia tongji ju [National Bureau of Statistics of China]. 2013a. "China's Economy Achieved a Stabilized and Accelerated Development in the 
Year of 2012” [English press release], January 18.

http://www.stats.gov.cn/english/PressRelease/201301/t20130118_72247.html 